\title{
Study of point defects in CdTe and CdTe:V by cathodoluminescence
}

\author{
U. Pal, J. Piqueras, and P. Fernández \\ Departamento de Física de Materiales, Facultad de Fisicas, Universidad Complutense, \\ 28040 Madrid, Spain \\ M. D. Serrano and E. Dieguez \\ Departamento de Física de Materiales, Universidad Autónoma, 28049 Cantoblanco-Madrid, Spain
}

(Received 4 January 1994; accepted for publication 31 May 1994)

Cathodoluminescence in the scanning electron microscope has been used to investigate the relationship of point defects in $\mathrm{CdTe}$ and $\mathrm{CdTe}: \mathrm{V}$ with luminescence bands at 1.40 and $1.13 \mathrm{eV}$. V has been found to inhibit the $1.40 \mathrm{eV}$ luminescence. Annealing experiments indicate that $\mathrm{Cd}$ and $\mathrm{Te}$ vacancies are involved in the mentioned emission bands.

\section{INTRODUCTION}

The defect structure of CdTe substrates has often been investigated with luminescence techniques. In particular, a luminescence band normally referred as the $1.40 \mathrm{eV}$ band, has been associated with recombination processes involving defects but its nature seems to be complex. Myers et al. ${ }^{1}$ in their photoluminescence study of CdTe wafers concluded that a significant part of the $1.40 \mathrm{eV}$ band is directly related to surface damage. In other luminescence works ${ }^{2-4}$ it was found that the emission is also related to bulk defects. Photoluminescence and optical detected magnetic resonance have been used ${ }^{5,6}$ to study intrinsic defects in $\mathrm{CdTe}$ and to relate them to luminescence bands. It has been concluded in Refs. 5 and 6 that the $A$ center (cation vacancy-donor pair) is involved in the $1.40 \mathrm{eV}$ emission. On the other hand a luminescence band in CdTe at about $1.10-1.15 \mathrm{eV}$ has also been reported. ${ }^{6,7}$ The optical detected and conventional spin resonance measurements ${ }^{6}$ indicate that the $1.15 \mathrm{eV}$ emission is related to tellurium vacancies. In the present work cathodoluminescence (CL) in the scanning electron microscope is used to investigate the relationship of vacancies in CdTe with the mentioned luminescence bands. Since some impurities appearing in the divalent state in CdTe are situated on substitutional cadmium sites, ${ }^{8}$ they could influence the cadmium vacancy concentration and the appearance of the corresponding luminescence band. In order to investigate this effect, vanadium doped $\mathrm{CdTe}$ was used in addition to undoped material.

\section{EXPERIMENTAL METHOD}

The crystals used in this work were grown by the vertical Bridgman technique with the displacement of the furnace, using $\mathrm{Cd}$ and $\mathrm{Te} 6 \mathrm{~N}$ Cominco as starting materials. For the V-doped crystal, $\mathrm{V}$ metal Johnson-Matthey $99.5 \%$ was added to the melt in a concentration of $7 \times 10^{19}$ at $\mathrm{cm}^{-3}$. The wafers were prepared by mechanical polishing with alumina powder, tollowed by chemical polishing with a $2 \%$ brominemethanol solution. Some samples were annealed under an argon flux at $600{ }^{\circ} \mathrm{C}$ for $5 \mathrm{~h}$. Cross-sectional observations of the wafers, which had a thickness of about $800 \mu \mathrm{m}$ were performed on fresh cleaved surfaces.

The samples were observed in a Hitachi S-2500 scanning electron microscope in the emissive and CL modes at temperatures between 80 and $300 \mathrm{~K}$ with accelerating voltages of $25 \mathrm{keV}$. The experimental setup for spectral and panchromatic CL measurements with a North Coast EO-817 germanium detector has been previously described. ${ }^{9}$ In order to separate the contribution of the different bands from the CL image, optical filters were adapted in some cases to the detector entrance. Previous results ${ }^{4}$ show that CL spectra of CdTe recorded with a focused and defocused electron beam are different as a consequence of the presence of radiative centers with low concentration. For this reason CL spectra were recorded under different focusing conditions of the electron beam on the sample.

\section{RESULTS}

Figure 1 shows typical panchromatic CL images with bright subboundaries and bright spots inside the subgrains. The appearance of CL images in undoped and V-doped samples is similar but the subboundaries of the latter show a certain structure. Figure 2 shows CL spectra at $80 \mathrm{~K}$ of an undoped CdTe sample. With a focused electron beam only the exciton band peaking at $1.54 \mathrm{eV}(805 \mathrm{~nm})$ is observed. Defocusing the spectrum shows the $1.40 \mathrm{eV}(885 \mathrm{~nm})$ band as well as an increase of background cmission. The spatial distribution of both bands has been previously found ${ }^{4}$ to be different. The $1.4 \mathrm{eV}$ emission decreases from the border to the center of the wafer while the $1.54 \mathrm{eV}$ shows opposite behavior. In CdTe: $\mathrm{V}$ samples only the exciton band is observed even when the electron beam was defocused. Previous optical studies ${ }^{4}$ have shown that the $1.40 \mathrm{eV}$ band observed in the undoped CdTe is related to bulk defects. Figure 3 shows CL spectra of an undoped sample after annealing. In the focused spectrum a broad weak band centered at about $1.13 \mathrm{eV}(1100 \mathrm{~nm})$ appears in addition to the near band edge emission. By defocusing, the $1.13 \mathrm{eV}$ band drastically increases and becomes the only resolved band in the spectrum. Occasionally the $1.40 \mathrm{eV}$ emission appears as a shoulder of the broad $1.13 \mathrm{eV}$ band or is observed as an independent band in focused spectra. Annealing causes the appearance of $1.13 \mathrm{eV}$ emission also in the vanadium doped samples, as Fig. 4 shows, when the electron beam is defocused. However, the $1.40 \mathrm{eV}$ band is not observed in Fig. 4. In order to check if this is due to some annealing induced surface effect which inhibits the observation of the $1.4 \mathrm{eV}$ emission, the 
(a)

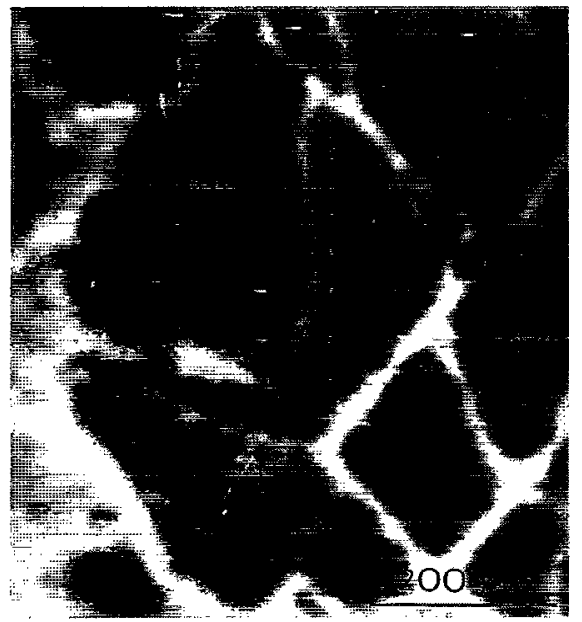

(b)

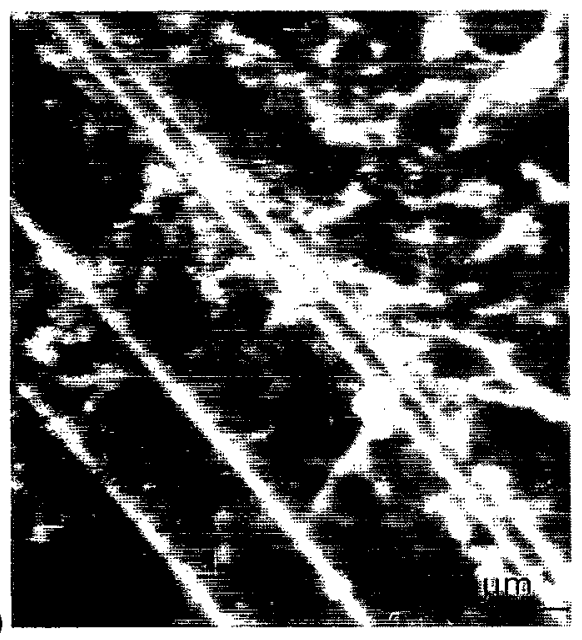

FIG. 1. Panchromatic CL image of (a) undoped CdTe and (b) CdTe:V at $80 \mathrm{~K}$.

samples were cleaved and the lateral surface observed by CL. Figure 5 shows the spectra obtained in such crosssectional observations in which both bands, 1.40 and 1.13 eV, are present.

Annealing does not cause changes in the panchromatic $\mathrm{CL}$ image of the undoped samples. Since the $1.13 \mathrm{eV}$ emission is intense only under a defocused condition it is not possible to get a clear CL image showing its space distribution in the sample. On the other hand the appearance of CL images in $\mathrm{V}$ doped samples changes markedly with annealing. Instead of the well-defined bright subboundaries of the unannealed samples, dark regions appear in a brighter background (Fig. 6). The contrast decreases in images recorded with the $1000 \mathrm{~nm}$ filter.

\section{DISCUSSION}

As stated above the $1.40 \mathrm{eV}$ band in CdTe has a complex nature with contributions from surface and bulk defects including A-type centers. The different behavior of undoped and $V$-doped samples, observed in this work, could be related to the involvement of $\mathrm{Cd}$ vacancies-through $\mathrm{A}$ centers-in

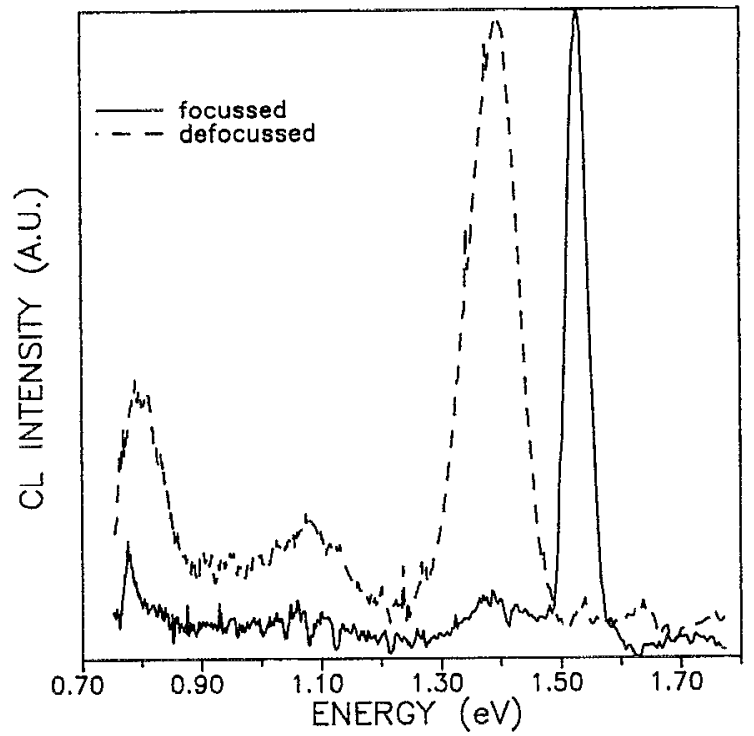

FIG. 2. CL spectra of undoped CdTe, recorded at $80 \mathrm{~K}$.

the $1.40 \mathrm{eV}$ emission. According to Ref. $8 \mathrm{~V}$ is situated on substitutional cadmium sites in CdTe. This is consistent with the fact that ionic radius of $\mathrm{V}(0.74 \AA)$ is much closer to the value for $\mathrm{Cd}(0.97 \AA)$ than for Te $(2.21 \AA)$. A high concentration of $\mathrm{V}$ impurities can reduce the $\mathrm{Cd}$-vacancy concentration and hence reduce the possibility of A center formation.

Annealing in an inert gas flow at $600^{\circ} \mathrm{C}$ causes the formation of cadmium and tellurium vacancies ${ }^{10}$ and can therefore influence the luminescence at 1.4 and $1.13 \mathrm{eV}$ in both kinds of samples. This is in fact observed in the spectra of Figs. 3 to 5. In Fig. 3 the $1.13 \mathrm{eV}$ peak related to Te vacancies dominates the spectrum of the annealed undoped samples.

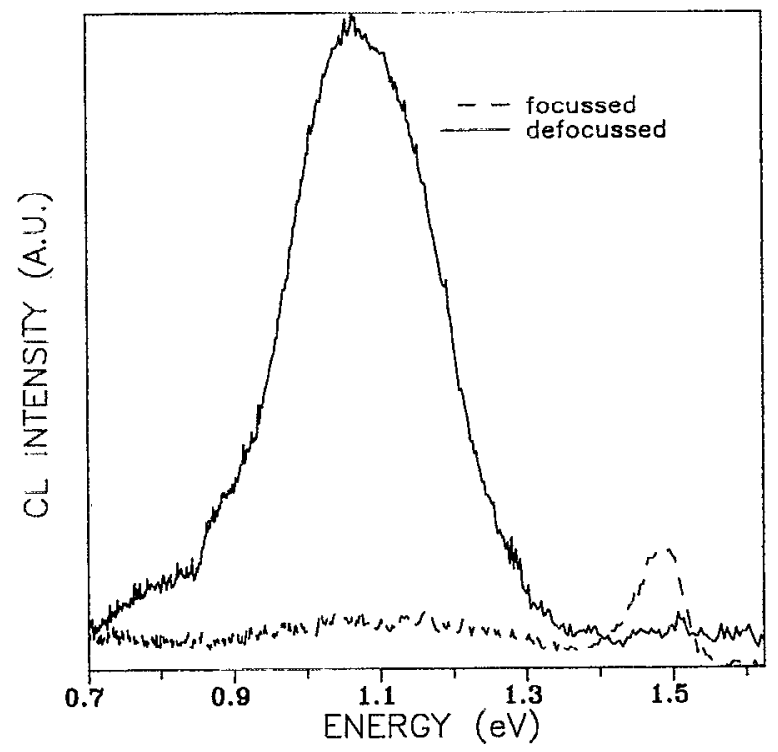

FIG. 3. CL spectra of undoped CdTe after thermal annealing, recorded at $80 \mathrm{~K}$. 


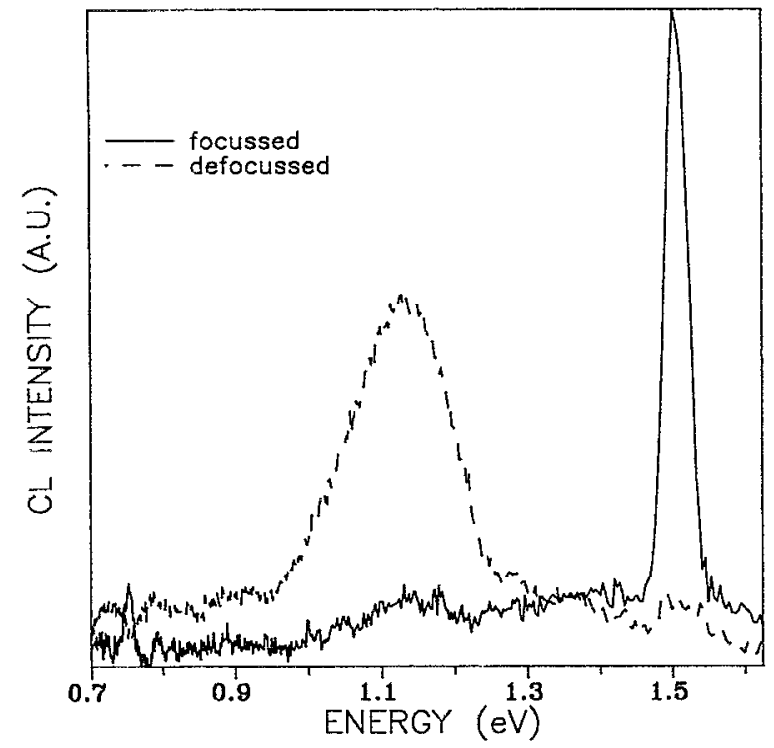

FIG. 4. CL spectra of CdTe: $\mathrm{V}$ after thermal annealing, recorded from the surface at $80 \mathrm{~K}$.

The $1.40 \mathrm{eV}$ band already present before annealing, is also observed in some regions of the same samples.

The effect of annealing is more evident in $\mathrm{V}$ doped material. The unannealed samples had only near band edge emission and the thermal treatment causes the appearance of the two bands. In the spectrum obtained in plan view observation (Fig. 4) only the $1.13 \mathrm{eV}$ emission appears while in cross-sectional observation (Fig. 5) both, 1.40 and $1.13 \mathrm{eV}$ bands are observed. This indicates that cadmium and tellurium vacancies are generated during annealing, influencing the deep level emission, but some surface effect inhibits the $1.40 \mathrm{eV}$ emission in the near surface region. This effect is probably related to the rates of metal and chalcogen evapo-

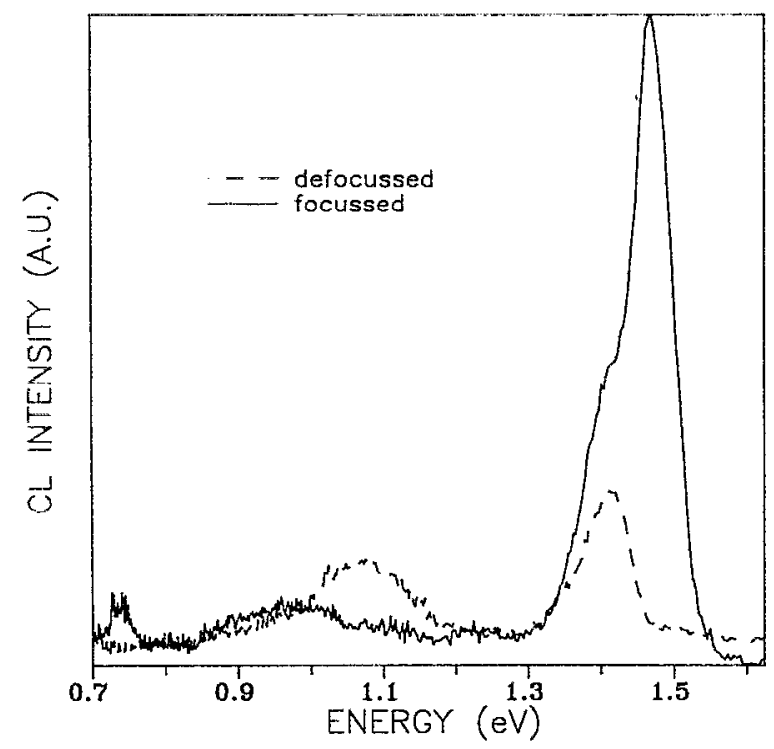

FIG. 5. CL spectra of CdTe:V after thermal annealing, recorded from the cleaved edge at $80 \mathrm{~K}$.

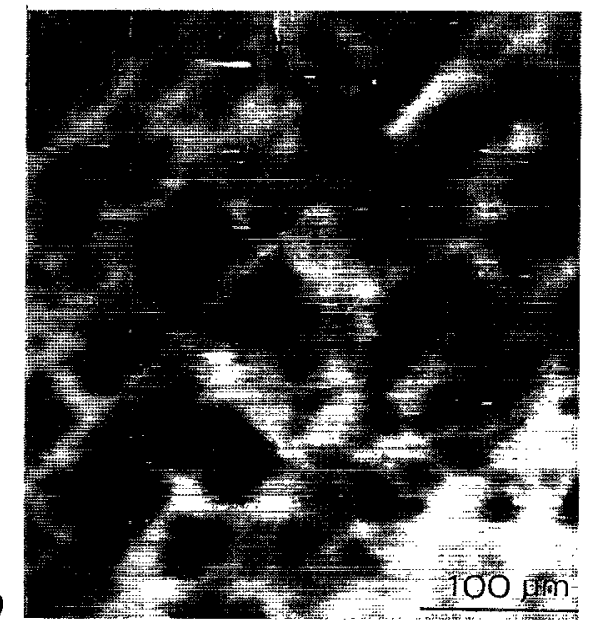

(b)

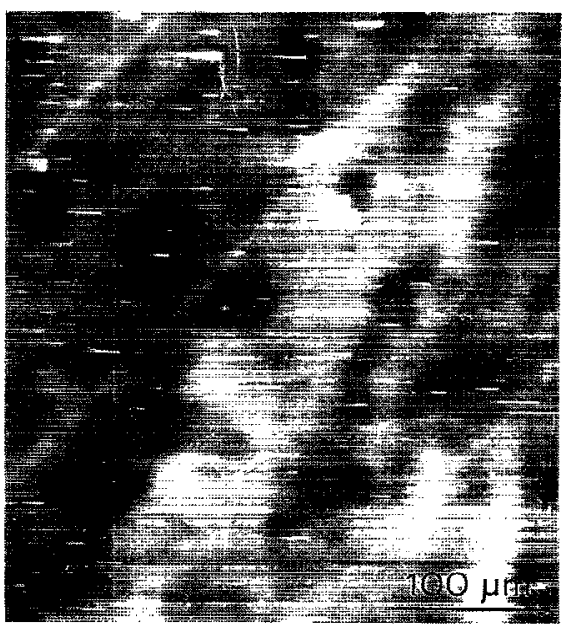

FIG. 6. CL images of annealed CdTe:V (a) panchromatic, (b) with $1000 \mathrm{~nm}$ cut-on filter.

ration in the course of thermal annealing which can result in the formation of a nonstoichiometric film in the surface as discussed in Ref. 10. The spectrum of Fig. 5 showing two bands additional to band edge emission is more representative of the annealing effect. The present results, influence of $\mathrm{V}$ doping and annealing on luminescence from CdTe, agree with the suggestion that cadmium and tellurium vacancies are involved in the 1.40 and $1.13 \mathrm{eV}$ luminescence, respectively.

Filtered CL images provide information on the space distributions of the defects related to the annealing induced luminescence. Drastic changes are observed in V-doped samples (Fig. 6). Panchromatic and deep level luminescence show a space distribution that cannot be easily related to a subgrain structure. In the annealed samples dark blobs appear in a bright background which indicates a redistribution of luminescent centers during annealing. This could be related to $\mathrm{V}$ diffusion similar to the case of $\mathrm{Cu}$ in $\mathrm{CdTe}$ described in Ref. 11.

\section{CONCLUSIONS}

$\mathrm{V}$ impurities in CdTe inhibit the appearance of $1.4 \mathrm{eV}$ luminescence. Annealing in inert atmosphere causes the ap- 
pearance of 1.4 and $1.13 \mathrm{eV}$ emission bands. In annealed undoped CdTe the CL spectrum is dominated by the $1.13 \mathrm{eV}$ band. Results agree with the possibility that both kinds of vacancies are related to the observed luminescence. CL images indicate that annealing induced luminescence centers are rather homogeneously distributed in the sample.

\section{ACKNOWLEDGMENTS}

U. Pal thanks MEC for a post-doctoral research grant. This work has been supported by DGICYT (Project PB 901017).

${ }^{1}$ T. H. Myers, J. F. Schetzina, S. T. Edwards, and A. F. Schrein, J. Appl. Phys. 54, 4232 (1983).

${ }^{2}$ L. O. Bubulac, J. Bajaj, W. E. Termant, P. R. Newman, and D. S. Lo, J. Cryst. Growth 86, 536 (1988).
${ }^{3}$ H. L. Cotal, A. C. Lewandowski, B. G. Markey, S. W. S. McKeever, E. Cantrell, and J. Aldridge, J. Appl. Phys. 67, 975 (1990).

${ }^{4}$ U. Pal, P. Fernández, J. Piqueras, M. D. Serrano, and E. Dieguez, Inst. Phys. Conf. Ser. 135, 177 (1993).

${ }^{5}$ D. M. Hoffmann, P. Omling, H. G. Grimmeiss, B. K. Meyer, K. W. Benz, and D. Sinerius, Phys. Rev. B 45, 6247 (1992).

${ }^{6}$ D. M. Hoffmann, W. Stadler, K. Oettinger, B. K. Meyer, P. Omling, M. Salk, K. W. Benz, E. Wiegel, and G. Müller-Vogt, Mater. Sci. Eng. B 16, 128 (1993).

${ }^{7}$ F. J. Bryant and E. Webster, Phys. Status Solidi 21, 315 (1967).

${ }^{8}$ P. A. Slodowy and J. M. Baramonski, Phys. Status Solidi B 49, 499 (1972).

${ }^{9}$ F. Domínguez-Adame, J. Piqueras, and P. Fernández, Appl. Phys. Lett. 58, 257 (1991).

${ }^{10}$ N. E. Korsanskaya, U. V. Markevich, and M. K. Sheinkman, J. Cryst. Growth 101, 285 (1990).

${ }^{11}$ J. P. Chamonal, E. Molva, M. Dupuy, R. Accomo, and J. L. Pautrat, Physica B 116, 519 (1983). 
Journal of Applied Physics is copyrighted by the American Institute of Physics (AIP). Redistribution of journal material is subject to the AIP online journal license and/or AIP copyright. For more information, see http://ojps.aip.org/japo/japcr/jsp

Copyright of Journal of Applied Physics is the property of American Institute of Physics and its content may not be copied or emailed to multiple sites or posted to a listserv without the copyright holder's express written permission. However, users may print, download, or email articles for individual use. 
Journal of Applied Physics is copyrighted by the American Institute of Physics (AIP). Redistribution of journal material is subject to the AIP online journal license and/or AIP copyright. For more information, see http://ojps.aip.org/japo/japcr/jsp 